\title{
AUTOAVALIAÇÃO DE COMPETÊNCIAS DigitAIS DE PEDAGOGAS DE UMA ESCOLA DE CRICIÚMA/SC
}

\author{
SELF-ASSESSMENT OF DIGITAL SKILLS OF PEDAGOGOS AT A SCHOOL IN \\ CRICIÚMA/SC
}

\section{Christie Pereira Albuquerque ${ }^{1}$ \\ Leila Laís Gonçalves ${ }^{2}$}

\begin{abstract}
RESUMO: A fluência do professor no uso das tecnologias digitais de comunicação e informação (TDIC) é temática recorrente em pesquisas e que tomou contornos muito particulares por conta da pandemia da COVID-19. Com o Ensino Remoto Emergencial, formato que possibilitou a continuidade da educação e mudou a prática dos professores, as competências digitais se tornaram essenciais para o trabalho docente. Diante disso, a pesquisa buscou analisar o nível de apropriação de competência digital de pedagogas do ensino fundamental anos iniciais de uma escola da rede municipal de Criciúma/SC. A opção metodológica adotada foi a pesquisa descritiva, bibliográfica e estudo de campo com abordagem quantitativa. O estudo abordou as TDIC e sua aplicação na educação, as competências digitais dos professores e a sua autoavaliação apontando instrumentos para autoavaliação. A pesquisa foi aplicada em uma escola da rede municipal de Criciúma/SC envolvendo oito pedagogas. Foi utilizado, como instrumento de autoavaliação, o Guia EduTec do Cieb. A partir da descrição do cenário pesquisado e a interpretação dos resultados pôde-se concluir que, de forma geral, os professores usam pontualmente as tecnologias como apoio ao ensino, caracterizando a apropriação como nível de familiarização. Com os resultados da pesquisa espera-se contribuir na reflexão sobre a apropriação para o uso de TDIC na prática pedagógica e com informações para o planejamento de jornadas formativas mais efetivas envolvendo os recursos tecnológicos.
\end{abstract}

PALAVRAS-CHAVE: Competências Digitais do Professor. Avaliação de Competências Digitais. Instrumento de autoavaliação. Tecnologia Digital de Informação e Comunicação.

\begin{abstract}
The teacher's fluency in the use of digital communication and information technologies is a recurrent theme in research and that took on very particular contours due to the COVID-19 pandemic. With Emergency Remote Teaching, a format that enabled the continuity of education and changed the practice of teachers, digital skills became essential for the teaching work. Therefore, the research sought to investigate the level of appropriation of digital

\footnotetext{
${ }^{1}$ Acadêmica do curso de Pedagogia da UNESC. pedagogia@unesc.net

2 Doutoranda em Educação pelo PPGE/ UNESC. 1lg@ unesc.net

Saberes Pedagógicos, Criciúma, v. 5, n², maio/agosto 2021.- Curso de Pedagogia- UNESC
} 
competences of elementary school pedagogues in the early years of a school in the municipal network of Criciúma/SC. The methodological option adopted was descriptive, bibliographical research and field study with a quantitative approach. The study addressed digital communication and information technologies and its application in education, teachers' digital competences and the self-assessment of teachers' digital competences, pointing out instruments for self-assessment. The research was applied in a school in the municipal network of Criciúma/SC involving eight pedagogues. The digital competence self-assessment instrument used was the Cieb EduTec Guide. The main results were the description of the digital competences of the teachers, the identification of self-assessment instruments and the levels of appropriation of the digital competences of the researched pedagogues. From the description of the researched scenario and the interpretation of the results, it was possible to conclude that, in general, teachers use technology punctually to support teaching, characterizing the appropriation as a level of familiarization. With the research results, it is expected to contribute to the reflection on the appropriation for the use of TDIC in pedagogical practice and with information for the planning of more effective training journeys involving technological resources.

KEYWORDS: Teacher's Digital Skills. Digital Skills Assessment. Self-Assessment Instrument. Digital Information and Communication Technology.

\section{INTRODUÇÃO}

A fluência do professor no uso das tecnologias digitais de comunicação e informação (TDIC) é uma temática que vem sendo discutida de longa data por educadores e pesquisadores, mas que tomou contornos muito particulares por conta da pandemia da COVID-19. Em virtude do fechamento das escolas, distanciamento social e outras restrições, professores dos diferentes níveis educacionais tiveram que adequar suas práticas, seus materiais e suas dinâmicas de trabalho aplicando recursos tecnológicos para possibilitar a continuidade da educação no formato do Ensino Remoto Emergencial. Nesse movimento, o professor precisou acessar ferramentas, ambientes e plataformas digitais; dominar um repertório de recursos para produção e compartilhamento de conteúdo; utilizar aplicativos; e buscar meios digitais para a mediação e interação com os estudantes. Esses profissionais, na maioria das vezes, tiveram pouca experiência prévia com plataformas, aplicativos e serviços web que se tornaram essenciais para condução do seu trabalho.

No curso de Pedagogia, havia algumas disciplinas que priorizavam o uso de laboratórios de informática, como a de Metodologia Científica e da Pesquisa e Ensino e Saberes Pedagógicos, Criciúma, v. 5, n², maio/agosto 2021.- Curso de Pedagogia- UNESC 
Aprendizagem no Mundo Digital. Foi, no entanto, com a emergência das aulas remotas que os professores passaram a empregar, de forma maciça, os recursos tecnológicos para a mediação das aulas. Como acadêmica do Curso de pedagogia, vivenciei esse processo de incorporação das TDIC na prática pedagógica dos meus professores, que até então envolvia o uso de ambiente virtual de aprendizagem (AVA) como plataforma de repositório conteúdo e de postagens de atividades. Nas aulas mediadas por tecnologia tivemos experiência com o uso do Google Meet e suas funcionalidades (enquetes, apresentação de trabalhos, compartilhamentos de tela, gravação das aulas), aplicativos como o Padlet, o Jamboard, o Mentimeter e o Socrative. A partir do estágio supervisionado, pudemos também acompanhar o processo na rede pública municipal, identificando necessidades relatadas pelos professores e seus pedidos de auxílio para uso de programas, aplicativos e plataformas as professoras. Ao me deparar com essa situação, desejei entender investigar o nível de apropriação e uso das TDIC pelos professores.

Diante desse cenário, é importante identificar, verificar e refletir sobre as competências necessárias para que o professor transite nesse cenário permeado pelas tecnologias digitais de comunicação e informação, as TDIC. Assim surge a pergunta problematizadora da pesquisa: "qual o nível de apropriação de competências digitais de pedagogos do ensino fundamental anos iniciais?". A pesquisa teve como objetivo geral, analisar o nível de apropriação de competência digital de pedagogas do ensino fundamental anos iniciais de uma escola da rede municipal de Criciúma/SC. Os objetivos específicos foram: descrever as características que qualificam as competências digitais dos professores a partir do referencial teórico tendo como base os estudos de Silva e Behar (2019); identificar instrumentos de autoavaliação, sendo pesquisados a Escala de Autoavaliação de Competências Digitais de Professores proposta por Dias, Moreira e Nunes (2017) e modelo de Autoavaliação dos Professores do Centro de Inovação para a Educação Brasileira (Cieb); identificar o nível de apropriação de competência digital dos professores utilizando instrumento de autoavaliação e discutir os resultados do nível de apropriação considerando os indicadores do modelo autoavaliação.

O artigo é estruturado em seis seções. As seções 2 e 3 apresentam a fundamentação teórica abordando os temas: Tecnologias Digitais de Informação e Comunicação (TDIC) e sua Saberes Pedagógicos, Criciúma, v. 5, n², maio/agosto 2021.- Curso de Pedagogia- UNESC 


\section{SABERES PEDAGÓGICOS}

Revista do Curso de Graduaçào de Pedagogia - Unesc

ISSN 2526.4559

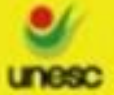

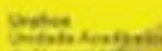

aplicação na educação, as competências digitais dos professores e a autoavaliação da apontando instrumentos para autoavaliação. A metodologia da pesquisa é descrita na seção 4. $\mathrm{Na}$ seção 5 são apresentados e discutidos os resultados. O artigo é finalizado com as conclusões e recomendações.

\section{TECNOLOGIAS DIGITAIS DE INFORMAÇÃO E COMUNICAÇÃO NA EDUCAÇÃO}

As TDIC são mídias, ferramentas, instrumentos e equipamentos que utilizam as tecnologias digitais, como notebooks, tablets, celulares, softwares, aplicativos entre outros. O número de tecnologias digitais cresce a cada dia e são utilizadas para os diferentes fins incorporando-se ao nosso cotidiano. Estamos imersos na Cultura Digital que, de acordo com Bortolazzo (2020), "envolve processos de comunicação, aparatos e dispositivos, espaços e práticas sociais que se encontram atrelados aos usos das tecnologias digitais".

O ensino remoto emergencial acelerou esse processo de transposição didática com o uso da tecnologia na educação, considerado um dos meios de dar continuidade às aulas. Muito se tem produzido, tanto no meio acadêmico, quanto também no meio comercial, em relação às práticas com usos das TDIC e ferramentas digitais para o ensino. Destacam-se tanto as práticas aplicadas transversalmente para apoiar a implementação da sequência didática ou como suporte para promover a construção de conhecimentos e aprendizagem, assim como as práticas cujo objeto do conhecimento seja a própria tecnologia (BRASIL, 2021). Ao mesmo tempo que, a utilização de páginas em redes sociais promove a disseminação das práticas pedagógicas e alcance de um número maior de pessoas favorecendo o compartilhamento.

Crespo e Crespo (2020) organizaram um E-book com ferramentas digitais e suas aplicações pedagógicas para subsidiar e catalisar as ações docentes nas ações remotas (síncronas e assíncronas) que podem também auxiliar nas aulas presenciais. As ferramentas digitais foram organizadas nas categorias: serviços de armazenamento de arquivo on-line, ambientes virtuais de aprendizagem (AVA), ferramentas para videoconferência, ferramentas para produção de vídeos e apresentações animadas, ferramentas para produção de quiz, ferramentas para produção de mapas mentais e infográficos, ferramentas para atividades Saberes Pedagógicos, Criciúma, v. 5, n², maio/agosto 2021.- Curso de Pedagogia- UNESC 
colaborativas, ferramentas para pessoas com necessidades educacionais especiais e banco de imagens. Além das ferramentas digitais, o E-book aborda conceitos e informações importantes para a análise das ferramentas. De forma semelhante, pode-se observar outras iniciativas como a elaboração do Guia e Implementação de Estratégias de Aprendizagem Remota (CIEB, 2020) e o E-book de Ferramentas Digitais para Professores (ANASTÁCIO; FRANÇA, 2020).

Para utilizar os recursos, sejam eles analógicos ou digitais, o professor precisa de conhecimentos, habilidade e atitudes que o capacitem. De acordo com Freire (1997, p.102 e 103),

\begin{abstract}
A segurança com que a autoridade docente se move implica uma outra, viu isso aqui se funda na sua competência profissional. Nenhuma autoridade docente se exerce ausente desta competência. $O$ professor que não leve a sério sua formação, que não estude, que não se esforce para estar à altura de sua tarefa não tem força moral para coordenar as atividades de sua classe.
\end{abstract}

O significado do conceito de competência varia de acordo com a argumentação presente no discurso, como também em relação ao controle ideológico que se pretende alcançar. Para Fairclough (2001) no contexto do discurso educacional, o vocabulário de habilidades é prevalente incluindo termos como "habilidade" e "competência". Na análise feita pelo autor, o conceito de habilidades pressupõe duas construções contraditórias deixando pouco espaço à individualidade (FAIRCLOUGH, 2001, p. 257):

\begin{abstract}
tem implicações ativas e individualistas: habilidades são atributos apreciados pelos indivíduos, estes diferem em tipos e graus de habilidade, e está aberto a cada um aperfeiçoar as habilidades ou acrescentar novas habilidades; tem implicações normativas, passivas e objetificadoras: todos os indivíduos adquirem elementos de um repertório social comum de habilidades por meio de procedimentos de treinamento institucionalizados.
\end{abstract}

Um documento publicado pela UNESCO intitulado "Padrões de Competência em TIC para professores" teve como objetivo "oferecer um conjunto básico de qualificações, que permita aos professores integrarem as TIC ao ensino e à aprendizagem, para o desenvolvimento do aprendizado do aluno e melhorar outras obrigações profissionais" (UNESCO, 2009). De acordo com o documento, os professores precisam adquirir a competência no uso da tecnologia que lhes possibilite proporcionar suporte ao aprendizado e ofertar autonomia aos estudantes compreendendo serem tais habilidades necessárias no 
repertório de qualquer profissional docente. $\mathrm{Na}$ análise de discurso do documento, Silva (2019) alerta que o "enfoque de competências em educação remete à racionalidade técnica das formas de ensino e à despolitização das práticas educativas quando não considera a autonomia do professor e seu conhecimento tácito".

A Base Nacional Comum Curricular $(\mathrm{BNCC})^{3}$ é um documento normativo que estabelece conhecimentos, competências e habilidades a serem desenvolvidos pelos estudantes ao longo da escolaridade básica. Na Base (BRASIL, 2018), competência é definida como "a mobilização de conhecimentos (conceitos e procedimentos), habilidades (práticas, cognitivas e socioemocionais), atitudes e valores para resolver demandas complexas da vida cotidiana, do pleno exercício da cidadania e do mundo do trabalho". O documento aponta para o desenvolvimento de competências relacionadas ao uso crítico e responsável das tecnologias digitais, tanto de forma transversal presentes em nas áreas do conhecimento e destacadas em diversas habilidades com objetos de aprendizagem variados, quanto de forma direcionada tendo como fim o desenvolvimento de competências relacionadas ao próprio uso das tecnologias, recursos e linguagens digitais. Dentre as dez competências gerais preconizadas pela BNCC, a quinta competência, a Cultura digital, tem como foco a compreensão, uso e criação de TDIC em diversas práticas sociais, assim definida:

\footnotetext{
Compreender, utilizar e criar tecnologias digitais de informação e comunicação de forma crítica, significativa, reflexiva e ética nas diversas práticas sociais (incluindo as escolares) para se comunicar, acessar e disseminar informações, produzir conhecimentos, resolver problemas e exercer protagonismo e autoria na vida pessoal e coletiva. (BRASIL, 2018, p.9).
}

A BNCC indica o Currículo de Referência em Tecnologia e Computação do Cieb como apoio para a construção de currículos escolares e de propostas pedagógicas que contemplem tal uso "ativo" das TDIC nas escolas. O currículo prevê eixos, conceitos e habilidades alinhadas à BNCC e voltadas para o desenvolvimento de competências digitais e de uso das tecnologias nas escolas, além de propor uma reflexão sobre os usos das TDIC.

Ainda que em concordância com o posicionamento de Silva (2019) e Leher (2010), em relação à visão tecnicista e ao determinismo tecnológico das políticas educacionais, sob

\footnotetext{
${ }^{3}$ A BNCC, homologada em 14 de dezembro de 2018 pelo Ministério da Educação, norteia os currículos dos sistemas e redes de ensino das Unidades Federativas brasileiras.

Saberes Pedagógicos, Criciúma, v. 5, n², maio/agosto 2021.- Curso de Pedagogia- UNESC
} 
influência de Organismos Internacionais, na pesquisa buscou-se observar aspectos para além da perspectiva tecnológica e instrumental. Nesse sentido, foram observadas na literatura diferentes construções do conceito de competência digital, em especial para professores. Silva e Behar (2019) fazem uma revisão sistemática acerca do conceito de competência digital na Educação sintetizando: "o que se espera de um sujeito digitalmente competente é que este possa compreender os meios tecnológicos o suficiente para saber utilizar as informações, ser crítico e ser capaz de se comunicar utilizando uma variedade de ferramentas".

Dentre os elementos comuns no conceito de competência digital dos autores abordados no estudo de Silvia e Behar (2019) destacam-se:

\begin{abstract}
A mobilização de conhecimentos, habilidades e atitudes (conhecido como CHA) necessários para que o sujeito atue por meio das tecnologias; a ética para utilizar adequadamente as tecnologias a partir do uso seguro e crítico das tecnologias de informação para o trabalho, para o lazer e para a comunicação; a capacidade de explorar e enfrentar as novas situações tecnológicas de uma maneira flexível; e o aproveitamento do potencial tecnológico com o fim de representar e resolver problemas, e construir conhecimento compartilhado e colaborativo, enquanto se fomenta a consciência de suas próprias responsabilidades pessoais e o respeito recíproco dos direitos e obrigações.
\end{abstract}

Para a pesquisa, adotou-se o conceito de competência digital de Ferrari (2012 apud SILVA; BEHAR, 2019) entendido como:

\begin{abstract}
Um conjunto de conhecimentos, habilidades e atitudes, estratégias e sensibilização de que se precisa quando se utilizam as TIC e os meios digitais para realizar tarefas, resolver problemas, se comunicar, gestar informação, colaborar, criar e compartilhar conteúdo, construir conhecimento de maneira efetiva, eficiente, adequada de maneira crítica, criativa, autônoma, flexível, ética, reflexiva para o trabalho, o lazer, a participação, a aprendizagem, a socialização, o consumo e o empoderamento.
\end{abstract}

A partir deste conceito, se pode estabelecer relações mais pontuais entre letramento e fluência digitais, que serão abordados na sequência.

\title{
3 AUTOVALIAÇÃO DE COMPETÊNCIAS DIGITAIS DE PROFESSORES
}

A diferença entre ser digitalmente letrado ou digitalmente fluente, definida por Briggs e Makice (2011), está em saber não só o que fazer com a tecnologia e como fazê-lo, mas 
também quando e por que usá-la. Saber usar, do ponto de vista técnico, as ferramentas digitais qualifica o sujeito como letrado digital, já compreender efetivamente a tecnologia digital sabendo aplicá-la de forma produtiva no trabalho e na vida quotidiana se configura como fluente digital. Estar consciente da validade da fluência digital e identificar como estão as competências digitais para o exercício da profissão docente são formas de exercer o protagonismo para o desenvolvimento profissional e um apoio para inovação na prática pedagógica.

Uma estratégia para conhecer a proficiência em um dado conhecimento é a autoavaliação. De acordo com Punhagui (2012), a autoavaliação configura-se como uma perspectiva de aprendizagem permitindo a regulação do próprio desempenho e a possibilidade de reconhecer fortalezas e fragilidades. Bailey (1981 apud PUNHAGUI, 2012) afirma que a autoavaliação é essencial para o desenvolvimento profissional de professores sendo que o autoexame possibilita direcionar as decisões para formação e atuação profissional.

Nesse sentido, instrumentos de autoavaliação podem ser utilizados possibilitando identificar níveis de proficiência ou de apropriação das tecnologias digitais nas áreas de abrangência da atuação docente. Como ferramentas de autoavaliação estruturadas, validadas e em português citam-se o DigCompEdu CheckIn e o Guia Edutec.

O DigCompEdu CheckIn (traduzido por DIAS-TRINDADE; MOREIRA, 2018) é um questionário desenvolvido pelo EU Science Hub, departamento da União Europeia, que possibilita a identificação do nível de competência digital e fornece informações de como o professor pode se aperfeiçoar. O instrumento é composto de vinte e uma questões organizadas em seis áreas estruturantes considerando as competências do professor para o uso de tecnologias e recursos digitais: 1) Envolvimento Profissional com foco na comunicação, colaboração e evolução profissional; 2) Tecnologias e Recursos Digitais, considerando capacidade de usar, compartilhar e proteger as informações; 3) Ensino e Aprendizagem referente à capacidade para gerir e organizar o uso de tecnologias digitais no processo de ensino e aprendizagem; 4) Avaliação que trata da utilização das tecnologias digitais no processo de avaliação dos estudantes; 5) Capacitação dos Estudantes referente à capacidade de utilizar as tecnologias digitais para aumentar a inclusão, personalização e o envolvimento ativo dos estudantes e 6) Promoção da Competência Digital dos Estudantes visando auxiliáSaberes Pedagógicos, Criciúma, v. 5, n², maio/agosto 2021.- Curso de Pedagogia- UNESC 
los no uso das tecnologias digitais de forma criativa e responsável. O nível da competência digital é dado de acordo com a pontuação final sendo atribuídos de 0 a 4 pontos, em um total de 84 pontos. O Nível de COMPETÊNCIA DIGITAL se dá de acordo com a pontuação assim classificado: A1- Recém-chegados (menos de 19 pontos); A2- Exploradores (entre 19 e 32 pontos); B1- Integradores (entre 33 e 47 pontos); B2- Especialistas (entre 48 e 62 pontos); C1Líderes (entre 63 e 77 pontos) e C2- Pioneiros (mais de 77 pontos).

O Guia EduTec (CIEB, 2020) é uma ferramenta online, desenvolvida pelo Cieb em parceria com o Instituto Natura e com a Rede Escola Digital, que possibilita aos docentes da educação básica identificarem suas competências digitais para que possam se desenvolver profissionalmente. Na elaboração da matriz de competência digital do Guia EduTec do Cieb foram consideradas as formuladas por organizações internacionalmente reconhecidas, como a Rede Enlaces do Chile, o International Society for Technology in Education (ISTE) dos Estados Unidos e da UNESCO.

A ferramenta do Cieb é composta por um questionário de 23 perguntas objetivas, com foco na autoavaliação de competência digital de professores para uso das TDIC, que mensura os níveis de apropriação. Estas competências demandam a capacidade de integrar a tecnologia de forma transversal e, para tanto, é fundamental que estejam preparados para adaptar suas práticas docentes ao dia a dia da sala de aula. As perguntas estão estruturadas em três áreas: pedagógica, cidadania digital e desenvolvimento profissional. As áreas abordam 12 competências: prática pedagógica; avaliação; personalização; curadoria e criação; uso responsável; uso seguro; uso crítico; inclusão; autodesenvolvimento; autoavaliação; compartilhamento e comunicação. As 12 competências necessárias para que professores utilizem as tecnologias de informação e comunicação de forma efetiva na educação e suas respectivas áreas foram sistematizadas pelo Cieb no quadro 1.

Quadro 1. Competências de professores para o uso de TICs

\begin{tabular}{|c|c|c|c|c|}
\hline Área & \multicolumn{4}{|c|}{ Competências } \\
\hline PEDAGÓGICA & $\begin{array}{l}\text { PRÁTICA PEDAGÓGICA } \\
\text { Ser capaz de incorporar } \\
\text { tecnologia às experiências } \\
\text { de aprendizagem dos } \\
\text { alunos e às suas estratégias } \\
\text { de ensino. }\end{array}$ & $\begin{array}{l}\text { AVALIAÇÃO } \\
\text { Ser capaz de usar } \\
\text { tecnologias digitais } \\
\text { para acompanhar e } \\
\text { orientar o processo de } \\
\text { aprendizagem e avaliar } \\
\text { o desempenho dos }\end{array}$ & $\begin{array}{l}\text { PERSONALIZAÇãO } \\
\text { Ser capaz de utilizar a } \\
\text { tecnologia para criar } \\
\text { experiências de } \\
\text { aprendizagem que atendam } \\
\text { às necessidades de cada } \\
\text { estudante. }\end{array}$ & $\begin{array}{l}\text { CURADORIA E } \\
\text { CRIAÇÃO } \\
\text { Ser capaz de selecionar } \\
\text { e criar recursos digitais } \\
\text { que contribuam para o } \\
\text { processo de ensino e } \\
\text { aprendizagem e gestão }\end{array}$ \\
\hline
\end{tabular}

Saberes Pedagógicos, Criciúma, v. 5, n², maio/agosto 2021.-Curso de Pedagogia- UNESC 


\begin{tabular}{|c|c|c|c|c|}
\hline & & alunos. & & de sala de aula \\
\hline $\begin{array}{l}\text { CIDADANIA } \\
\text { DIGITAL }\end{array}$ & $\begin{array}{l}\text { USO RESPONSÁVEL } \\
\text { Ser capaz de fazer e } \\
\text { promover o uso ético e } \\
\text { responsável da tecnologia } \\
\text { (cyberbullying, } \\
\text { privacidade, presença } \\
\text { digital e implicações } \\
\text { legais). }\end{array}$ & $\begin{array}{l}\text { USO SEGURO } \\
\text { Ser capaz de fazer e } \\
\text { promover o uso seguro } \\
\text { das tecnologias } \\
\text { (estratégias e } \\
\text { ferramentas de } \\
\text { proteção de dados). }\end{array}$ & $\begin{array}{l}\text { USO CRÍTICO } \\
\text { Ser capaz de fazer e } \\
\text { promover a interpretação } \\
\text { crítica das informações } \\
\text { disponíveis em mídias } \\
\text { digitais. }\end{array}$ & $\begin{array}{l}\text { INCLUSÃO } \\
\text { Ser capaz de utilizar } \\
\text { recursos tecnológicos } \\
\text { para promover a } \\
\text { inclusão e a equidade } \\
\text { educativa. }\end{array}$ \\
\hline $\begin{array}{l}\text { DESENVOLVIMENTO } \\
\text { PROFISSIONAL }\end{array}$ & $\begin{array}{l}\text { AUTODESENVOLVIME } \\
\text { NTO } \\
\text { Ser capaz de usar TIC nas } \\
\text { atividades de formação } \\
\text { continuada e de } \\
\text { desenvolvimento } \\
\text { profissional }\end{array}$ & $\begin{array}{l}\text { AUTOAVALIAÇÃO } \\
\text { Ser capaz de utilizar as } \\
\text { TIC para avaliar a sua } \\
\text { prática docente e } \\
\text { implementar ações } \\
\text { para melhorias }\end{array}$ & $\begin{array}{l}\text { COMPARTILHAMENTO } \\
\text { Ser capaz de usar a } \\
\text { tecnologia para participar e } \\
\text { promover a participação } \\
\text { em comunidades de } \\
\text { aprendizagem e trocas } \\
\text { entre pares. }\end{array}$ & $\begin{array}{l}\text { COMUNICAÇÃO } \\
\text { Ser capaz de utilizar } \\
\text { tecnologias para manter } \\
\text { comunicação ativa, } \\
\text { sistemática e eficiente } \\
\text { com os atores da } \\
\text { comunidade educativa. }\end{array}$ \\
\hline
\end{tabular}

Fonte: Cieb (2019)

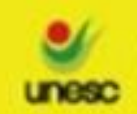

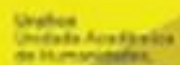

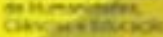

Para a definição dos níveis de apropriação do uso de tecnologias digitais, , o Cieb (2019) teve como base, estudos e modelos teóricos usados por pesquisadores, empresas, governos e instituições não governamentais, dentre eles: Apple Classrooms of Tomorrow (ACOT) dos Estados Unidos, o Modelo de Pasinato e Vosgerau do Brasil, European Framework for the Digital Competence of Educators (DigCompEdu) e a Ferramenta de Autoavaliação Tet-Sat do Mentoring Technology-Enhanced Pedagogy (MENTEP) da União Europeia. Foram definidos 5 níveis de a apropriação que evidenciam a progressão da competência digital pelo docente descritos no quadro 2.

Quadro 2. Níveis de Apropriação de Tecnologias

\begin{tabular}{|l|l|}
\hline Nível & Descrição \\
\hline 1. EXPOSIÇÃO & $\begin{array}{l}\text { Não há uso das tecnologias na prática pedagógica, apenas pessoal, ou requer apoio. } \\
\text { Tecnologias como instrumento, não como parte da cultura digital. }\end{array}$ \\
\hline 2. FAMILIARIZAÇÃO & $\begin{array}{l}\text { Conhecimento e uso pontual nas atividades como apoio ao ensino. O uso de tecnologias está } \\
\text { centrado no (a) professor (a). }\end{array}$ \\
\hline 3. ADAPTAÇÃO & $\begin{array}{l}\text { As tecnologias são usadas periodicamente e podem estar integradas ao planejamento das } \\
\text { atividades pedagógicas. As tecnologias como recursos complementares para a melhoria do } \\
\text { processo de ensino e aprendizagem. }\end{array}$ \\
\hline 4. INTEGRAÇÃO & $\begin{array}{l}\text { O uso das tecnologias é frequente no planejamento das atividades e na interação com os } \\
\text { alunos. As tecnologias estão integradas e contextualizadas no processo de ensino e } \\
\text { aprendizagem. }\end{array}$ \\
\hline 5. TRANSFORMAÇÃO & $\begin{array}{l}\text { Uso das tecnologias de forma inovadora, compartilhada e colaborativa para além da escola. } \\
\text { Maturidade digital: as tecnologias como ferramenta de transformação social. }\end{array}$ \\
\hline
\end{tabular}

Fonte: adaptado do Cieb (2019)

Os Níveis de Apropriação de Competências Digitais são descritos em até três aspectos:

Saberes Pedagógicos, Criciúma, v. 5, n², maio/agosto 2021.- Curso de Pedagogia- UNESC 
1. Fluência no uso de tecnologias digitais identificando evidências do uso de tecnologias no contexto pessoal e pedagógico;

2. Integração das tecnologias digitais ao currículo com evidências sobre o uso de tecnologias alinhado aos documentos orientadores da rede de ensino e da escola;

3. Empoderamento dos alunos pontuando evidências da participação ativa dos alunos nos processos de ensino e de aprendizagem com o uso de tecnologias.

Os três aspectos estão presentes nas áreas pedagógica, cidadania digital e na área desenvolvimento profissional há presença apenas do aspecto Fluência no uso de tecnologias digitais.

Após responder todas as perguntas da autoavaliação, o professor tem acesso a uma devolutiva personalizada que indica o seu nível de apropriação quanto aos conhecimentos e usos que fazem das tecnologias digitais. Os resultados são apresentados por área e por competência.

\section{METODOLOGIA DA PESQUISA}

A análise sobre o nível de apropriação de competência digital dos professores considerando o uso efetivo da tecnologia, tanto para as atividades de ensino, quanto para o processo pessoal de atualização e desenvolvimento profissional demandou revisão bibliográfica envolvendo conceitos, características da prática docente no contexto das TDIC, as competências mobilizadas, modelos e instrumentos para a mensuração. A autoavaliação é uma estratégia que possibilita a identificação do grau de fluência no uso e integração das tecnologias nas práticas pedagógicas. Desta forma, considerando o objetivo, a opção metodológica adotada foi a pesquisa descritiva sendo utilizados como meios a pesquisa bibliográfica e de campo para o levantamento de dados com uso de questionário on-line. Tanto para coleta, quanto para análise dos resultados foi aplicada a abordagem quantitativa.

A pesquisa descritiva tem como propósito levantar as opiniões, atitudes e crenças de uma população apresentando uma realidade a partir da descrição, registro, análise e interpretação de fenômenos atuais (MARCONI; LAKATOS, 2017; GIL, 2017). A pesquisa quantitativa considera que tudo pode ser quantificável, o que significa traduzir em números Saberes Pedagógicos, Criciúma, v. 5, n², maio/agosto 2021.- Curso de Pedagogia- UNESC 


\section{SABERES PEDAGÓGICOS}

Revista do Curso de Graduaçào de Pedagogia - Unesc

ISSN 2526.4559

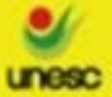

Uetotionesentis

opiniões e informações para classificá-las e analisá-las. Gil (2017) destaca que na pesquisa de campo, o pesquisador estuda somente um determinado grupo, realizando a maior parte da pesquisa pessoalmente, uma vez que o pesquisador precisa ter o contato com os fatos para depois analisá-los.

A pesquisa de campo foi realizada em uma escola municipal com as oito (8) pedagogas dos anos iniciais $\left(1^{\circ}\right.$ ao $5^{\circ}$ ano), sendo seis professoras diferentes por ano do $1^{\circ}$ ao $4^{\circ}$ e repetindo as professoras do $3^{\circ}$ e o $4^{\circ}$ anos no $5^{\circ}$ ano. Dentre as professoras participantes da pesquisa, cinco (5) professoras são efetivas e três (3) são contratadas pelo sistema municipal de ensino pela modalidade de Admissão em Caráter Temporário (ACT). A faixa etária das professoras é de 37 a 56. O instrumento de coleta utilizado foi o questionário online disponibilizado no Guia EduTec do Cieb, disponível no link: https://guiaedutec.com.br/educador. A escolha do instrumento se justifica pelo fato de estar disponibilizado na web, facilitando o acesso e a distribuição, por disponibilizar uma devolutiva detalhada ao professor e possuir avaliação de aspectos relevantes para a pesquisa. A Figura 1 apresenta as três áreas e as 12 competências abordadas nas 23 perguntas do questionário.

Figura 1. Composição do Questionário de Autoavaliação Guia EduTec

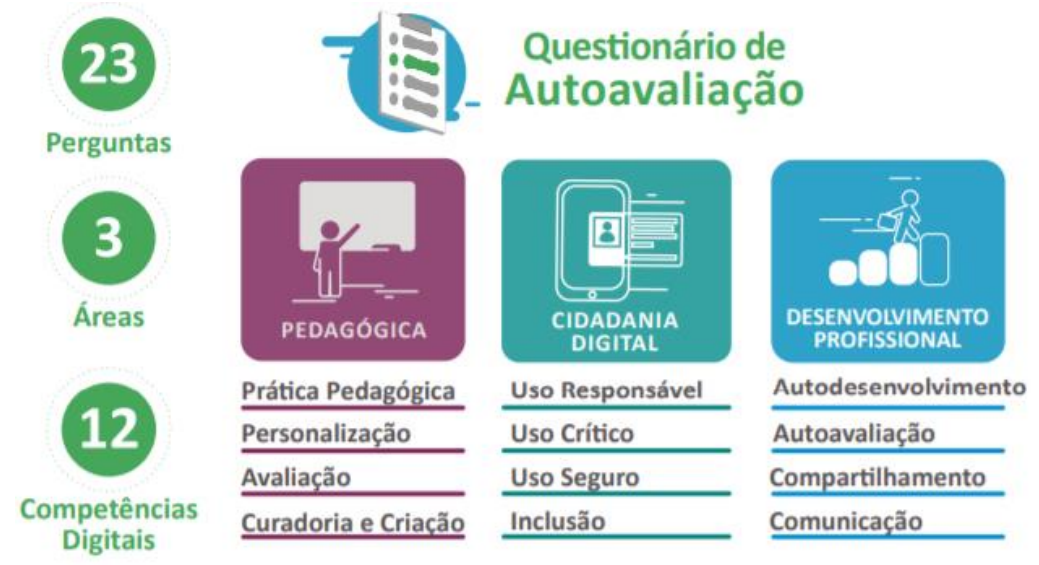

Fonte: Cieb (2019)

As professoras foram contatadas previamente e receberam, por e-mail, um formulário on-line do Termo de Livre Consentimento para participação da pesquisa e autorização para Saberes Pedagógicos, Criciúma, v. 5, n², maio/agosto 2021.- Curso de Pedagogia- UNESC 
uso dos dados, instruções e link para acesso ao questionário de autoavaliação. O período de resposta do questionário foi de 29/04/2021 a 02/05/2021. Após responder o questionário, as professoras foram orientadas a acessar a devolutiva com os resultados da autoavaliação, indicando os níveis de apropriação (exposição, familiarização, adaptação, integração e transformação) nas três áreas e nas 12 competências, e encaminhá-la ao pesquisador.

\section{APRESENTAÇÃO E ANÁLISE DE DADOS}

Para atender o objetivo da pesquisa que buscou identificar o nível de apropriação de competência digital de pedagogas do ensino fundamental anos iniciais de uma escola da rede municipal de Criciúma/SC, foram analisadas as respostas da devolutiva do Guia Edutec e do instrumento aplicado às professoras. Os resultados foram avaliados no âmbito geral e observados pontos que geram reflexões.

De forma geral, o nível de apropriação de competência digital dos professores participantes se situa no nível Familiarização. De acordo com os autores do questionário original, este nível refere que os respondentes possuem as características e aspectos evidenciados apresentados no Quadro 3.

Quadro 3. Características e aspectos do Nível - Familiarização

\begin{tabular}{|l|}
\hline Nível Familiarização \\
\hline $\begin{array}{l}\text { O professor começa a conhecer e usar pontualmente as tecnologias em suas atividades. Identifica e enxerga as } \\
\text { tecnologias como apoio ao ensino. O uso de tecnologias está centrado no professor. }\end{array}$ \\
\hline Empoderamento dos alunos: o uso das tecnologias digitais está centrado no ensino. \\
\hline $\begin{array}{l}\text { Integração das tecnologias ao currículo: o professor começa a conhecer e usar as tecnologias digitais em } \\
\text { suas atividades de forma pontual. }\end{array}$ \\
\hline $\begin{array}{l}\text { Fluência no uso de tecnologias: o professor enxerga as tecnologias digitais como apoio às atividades de } \\
\text { ensino, como a busca de recursos ou informações para preparar suas aulas. }\end{array}$ \\
\hline
\end{tabular}
Fonte: Cieb (2019)

Considerando as três áreas, a Pedagógica e Cidadania digital tiveram a classificação no nível Familiarização. Já na área de Desenvolvimento profissional, o prevalente foi o nível Adaptação que apresenta as características e aspectos conforme o Quadro 4. 
Quadro 4. Características e aspectos do Nível - Adaptação

\section{Nível Adaptação}

As tecnologias são usadas periodicamente e podem estar integradas ao planejamento das atividades pedagógicas. O professor identifica as tecnologias como recursos complementares para a melhoria do processo de ensino e aprendizagem.

Empoderamento dos alunos: o uso das tecnologias digitais está centrado no processo de aprendizagem dos alunos em sala de aula.

Integração das tecnologias ao currículo: caracteriza-se pelo uso frequente, embora não integrado ao planejamento de seu componente curricular.

Fluência no uso de tecnologias: o professor enxerga as tecnologias digitais como recursos complementares para a melhoria do processo de ensino e aprendizagem.

Fonte: Cieb (2019)

Observando o Gráfico 1, onde constam as médias de resposta em cada uma das 12 competências, verifica-se a competência "Autoavaliação" apresenta o valor mais alto. Já as competências "Curadoria e criação" e "Prática pedagógica" apresentam os valores mais baixos. Observam-se valores intermediários nas competências "Autodesenvolvimento", "Personalização" e "Uso crítico".

Gráfico 1. Resultados médios para as 12 Competências Digitais

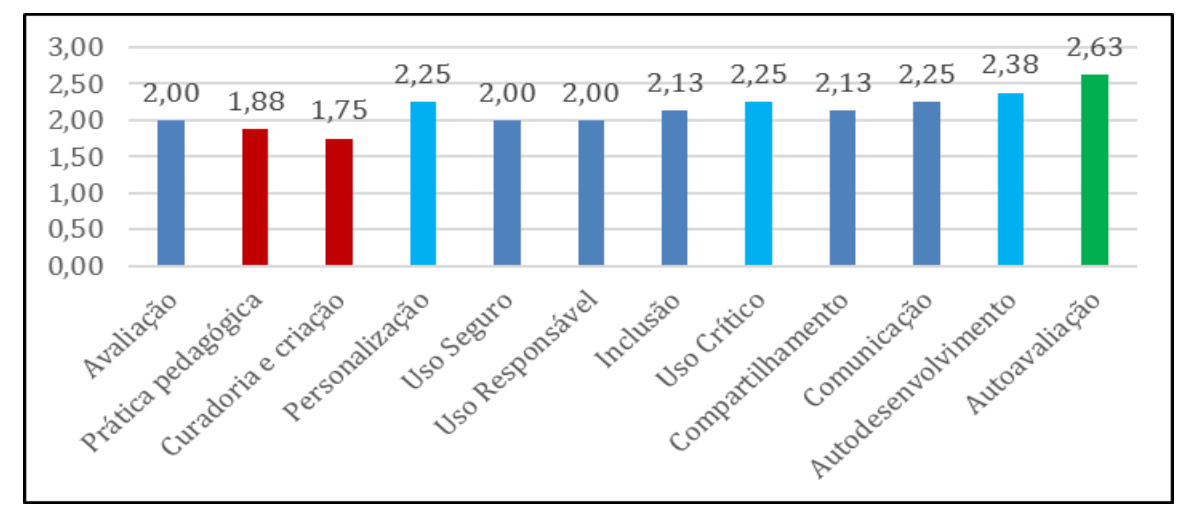

Fonte: do autor (2021).

A competência de "Autoavaliação", da área de Desenvolvimento profissional, referese à capacidade de utilizar as TDIC para avaliar a prática docente, refletir e buscar ações para melhorias. O nível de apropriação médio dessa competência é o de Adaptação traz como aspecto o da "Fluência no uso de tecnologias" evidenciando o uso de tecnologias digitais para registro e reflexão da prática docente. O resultado pode estar associado ao uso obrigatório de 
plataformas digitais para registro dos diários de classe nas escolas da rede municipal de Criciúma/SC.

A "Curadoria e criação", da área Pedagógica, cujo foco tem a seleção e a criação de recursos digitais que contribuam para o processo de ensino e aprendizagem, teve um resultado baixo. Nas respostas, três dos oito professores apresentaram o nível de apropriação Exposição e quatro pontuaram no nível Familiarização. Os aspectos do nível Exposição, para essa competência são apresentados no Quadro 5.

Quadro 5. Aspectos do Nível - Exposição para a Curadoria e criação

\section{Nível Exposição}

Empoderamento dos alunos: o professor não envolve os alunos na busca, na seleção ou na criação de conteúdos digitais.

Integração das tecnologias ao currículo: caracteriza-se pela falta de planejamento do uso de tecnologias digitais para curadoria ou criação de recursos digitais. Usa conteúdos digitais baixados da internet, porém sem o emprego de operadores de busca ou critérios objetivos.

Fluência no uso de tecnologias: o professor desconhece, não usa ou precisa de ajuda de algum colega para usar recursos básicos de busca ou de criação de conteúdos digitais.

Fonte: Cieb (2019)

Outro resultado de nível de apropriação baixo da área Pedagógica foi o da competência "Prática pedagógica". Nas respostas cinco dos oito professores apresentaram o nível Familiarização de apropriação e dois pontuaram no nível Exposição cujos aspectos apontados no Quadro 6.

Quadro 6. Aspectos do Nível - Exposição para a Prática Pedagógica

\section{Nível Exposição}

Empoderamento dos alunos: o professor não sabe, não usa ou precisa de ajuda para utilizar as tecnologias digitais na prática pedagógica com alunos

Integração das tecnologias ao currículo: caracteriza-se pelo desconhecimento, não uso ou necessita de ajuda para utilização das tecnologias digitais nas estratégias de ensino.

Fluência no uso de tecnologias: o professor desconhece, não usa ou precisa de ajuda para utilizar as tecnologias digitais no campo profissional. No campo pessoal, usa tecnologias de

comunicação, como correio eletrônico e aplicativos de mensagens instantâneas. Fonte: Cieb (2019)

Estes dois resultados, tanto da competência "Curadoria e criação", quanto da de "Práticas pedagógicas", se contrapõem ao levantado no referencial teórico que aponta o uso

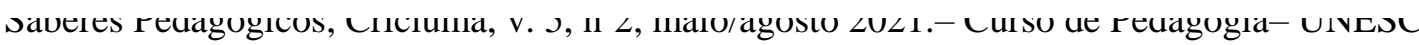




\section{SABERES PEDAGÓGICOS}

Revista do Curso de Graduaçào de Pedagogia - Unesc

ISSN 2526.4559

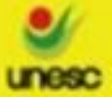

Uetotionentis

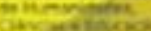

potencial das TDIC na Educação, em especial de ferramentas digitais e da internet como as descritas em Crespo e Crespo (2020).

A homogeneidade do grupo é observada nas competências "Avaliação", "Uso seguro" e "Uso responsável" com o nível Familiarização de apropriação. A maior diferença de resultados foi identificada na competência "Autodesenvolvimento", da área de Desenvolvimento profissional, com respostas entre os níveis Exposição, Familiarização, Adaptação e Integração. Observam-se também diferenças nas competências "Personalização" e "Uso crítico", também com respostas nos mesmos níveis, sendo o motivo de apresentarem valores intermediários.

Analisando o Gráfico 2, com os resultados médios das competências digitais dos professores obtidos por faixa etária, verifica-se que a proficiência diminui nos professores mais velhos (faixa etária de 50 a 60 anos) ficando mais próximo do nível Exposição, atingindo o nível Familiarização apenas na competência de "Autoavaliação". Os professores mais novos (faixa etária de 30 a 40 anos) apresentam mais resultados entre os níveis Familiarização e Adaptação.

Gráfico 2. Resultados Médios para as 12 Competências Digitais por Faixa Etária

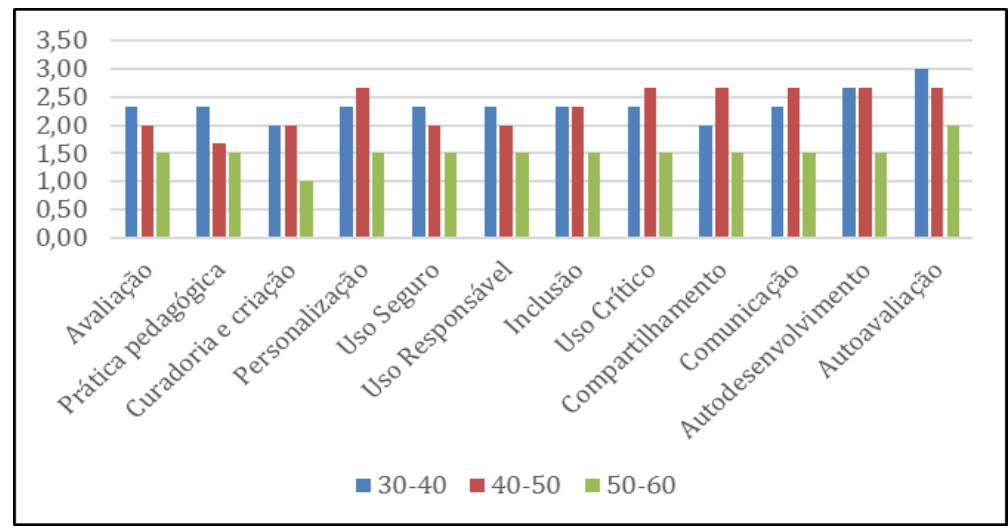

Fonte: do autor (2021).

Um ponto observado que chamou a atenção foi o resultado superior dos níveis de apropriação de uma das professoras em relação aos demais em todas as áreas pontuando nos níveis Adaptação e Integração, sendo pertencente a faixa etária intermediária (entre 40 e 50 


\section{SABERES PEDAGÓGICOS}

Revista do Curso de Graduaçào de Pedagogia - Unesc

ISSN 2526.4559

anos). A progressão linear de resultados por faixa etária fica evidenciada na retirada dos dados da professora que pontuou acima da média, conforme mostra o Gráfico 3.

Gráfico 3. Resultados médios para as 12 Competências Digitais por Faixa Etária

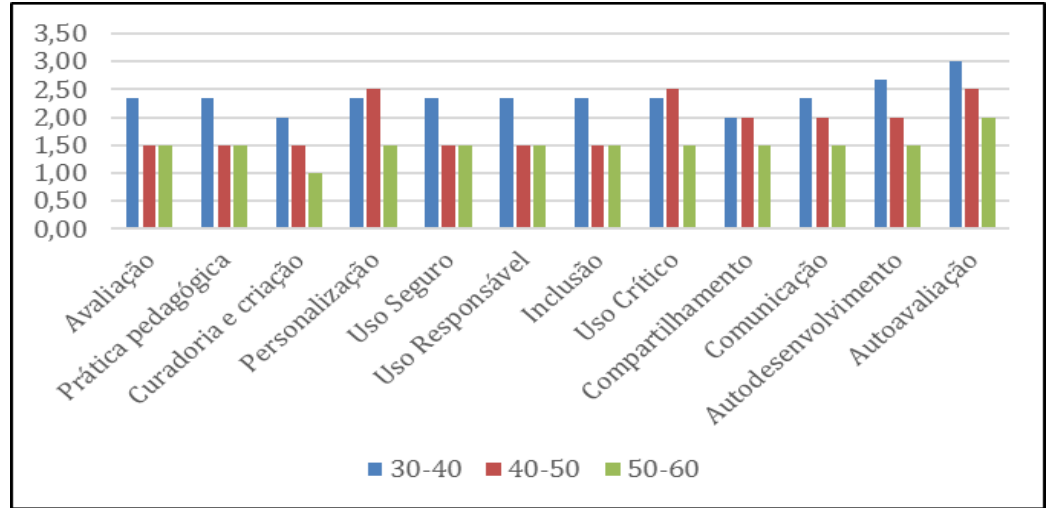

Fonte: do autor (2021).

Analisados os seus resultados médios para as 12 competências digitais por Ano (Gráfico 4), as participantes do $1^{\circ}$ Ano apresentam um nível de desempenho mais baixo na competência "Avaliação" e mais elevado na "Autoavaliação". Já as respondentes do $2^{\circ}$ Ano têm maior apropriação na competência de "Comunicação" e menor no "Uso responsável". No $3^{\circ}$ ano se observam resultados mais relevantes na "Avaliação" e "Uso responsável". O $4^{\circ}$ ano lidera na "Inclusão". Os resultados de nível de apropriação mais baixo de maneira geral são observados no $5^{\circ}$.

Gráfico 4. Resultados médios para as 12 Competências Digitais por Ano

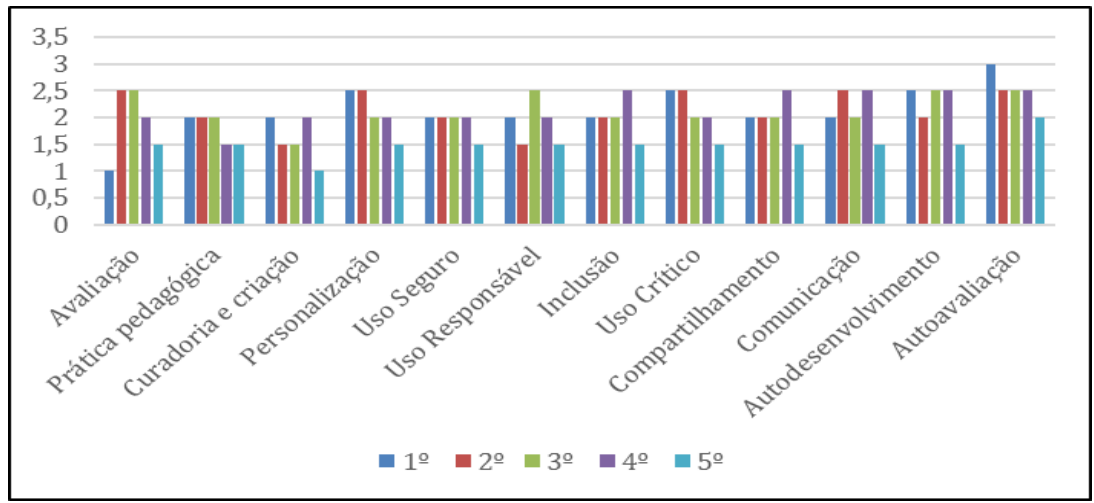

Fonte: do autor (2021).

Saberes Pedagógicos, Criciúma, v. 5, n², maio/agosto 2021.- Curso de Pedagogia- UNESC 


\section{CONCLUSÃO}

O objetivo geral da pesquisa visou investigar o nível de apropriação de competências digitais de pedagogas de uma escola da rede municipal de Criciúma/SC, sendo o mesmo foi alcançado com a aplicação do instrumento de autoavaliação e as análises dos resultados a partir do embasamento teórico. Com o levantamento bibliográfico foi possível identificar as características das competências digitais das professoras e estudar os instrumentos de autoavaliação DigCompEdu CheckIn e o Guia Edutec.

O Guia EduTec, questionário on-line para autoavaliação utilizado para coleta de dados e a devolutiva, possibilitaram a verificação dos níveis de apropriação das 12 competências (Prática pedagógica, Avaliação, Personalização, Curadoria e criação, Uso Responsável, Uso Seguro, Uso Crítico, Inclusão, Autodesenvolvimento, Autoavaliação, Compartilhamento e Comunicação) classificados em níveis de apropriação: Exposição; Familiarização; Adaptação; Integração e Transformação. Os principais resultados da pesquisa de campo, obtidos a partir da análise das devolutivas, são: o nível Adaptação de apropriação das pedagogas pesquisadas com o nível Familiarização; a competência com melhor desempenho foi a de "Autoavaliação" da área "Desenvolvimento profissional"; as competências com níveis Exposição, os mais baixos, foram a "Curadoria e criação" e "Prática pedagógica" da área "Pedagógica"; e o fator idade como interferente no nível de apropriação.

Para a continuidade da pesquisa, recomenda-se a autoavaliação para todos os professores da escola pesquisada e demais escolas da rede, com o uso do Guia EduTec. Com os resultados dessa pesquisa espera-se contribuir na reflexão sobre a apropriação para o uso de TDIC na prática pedagógica e com informações para o planejamento de jornadas formativas mais efetivas envolvendo os recursos tecnológicos.

\section{REFERÊNCIAS}

ANASTÁCIO, Liliane Rezende; FRANÇA, Renata de Souza. Ferramentas digitais para professores. Contagem/MG. Ed. Escola Cidadã, 2020. Disponível em: https://www.editoraescolacidada.com.br/2020/08/ferramentas-digitais-para-professores.html. Acesso em 10 abr. 2021.

Saberes Pedagógicos, Criciúma, v. 5, n², maio/agosto 2021.- Curso de Pedagogia- UNESC 


\section{SABERES PEDAGÓGICOS}

Revista do Curso de Graduaçào de Pedagogia - Unesc

ISSN 2526.4559

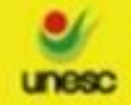

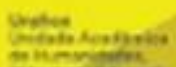

BORTOLAZZO, Sandro Faccin. Das conexões entre cultura digital e educação. ETD -

Educação Temática Digital, 22(2), 369-388. https://doi.org/10.20396/etd.v22i2.8654547.

2020.

BRASIL. Ministério da Educação. Base Nacional Comum Curricular. Brasília, DF., 2018.

Disponível em http://basenacionalcomum.mec.gov.br. Acesso em 10 abr. 2021.

Tecnologias Digitais da Informação e Comunicação no contexto escolar:

possibilidades. Disponível em

http://basenacionalcomum.mec.gov.br/implementacao/praticas/caderno-de-

praticas/aprofundamentos/193-tecnologias-digitais-da-informacao-e-comunicacao-no-

contexto-escolar-possibilidades Acesso em 10 abr. 2021.

BRIGGS, Christian.; MAKICE, Kevin. Digital Fluency: building success in the digital age. [S.1.]: SociaLens, 2011. Disponível em:

https://citeseerx.ist.psu.edu/viewdoc/downloaddoi=10.1.1.460.3 855\&rep= rep1\&type=pdf.

Acesso em 10 maio. 2021.

CANTINI, Marcos Cesar; et al. O desafio do professor frente às novas tecnologias. In:

CONGRESSO DE EDUCAÇÃO DA PUCPR, 6., 2006, Curitiba. Anais [...]. Curitiba:

Champagnat, 2006. p. 875-883. Disponível em:

https://sistemascmc.ifam.edu.br/educitec/index.php/educitec/article/view/1071. Acesso em: 18 jun. 2016.

CIEB. COMPETÊNCIAS DE PROFESSORES E MULTIPLICADORES PARA USO

DE TICS NA EDUCAÇÃO. [SÃO PAULO] - Nota Técnica 8 (16/04/19). Disponível em: https://cieb.net.br/wp-content/uploads/2019/06/CIEB-Notas-T\%C3\%A9cnicas-8COMPET\%C3\%8ANCIAS-2019.pdf. Acesso em: 10 mar. 2021.

. AUTOA VALIAÇÃO DE COMPETÊNCIAS DIGITAIS DE PROFESSORES.

[SÃO PAULO] - Nota Técnica 15 (06/05/19). Disponível em: https://cieb.net.br/wpcontent/uploads/2019/05/CIEB_NotaTecnica15_06-de-maio-de-2019.pdf. Acesso em: 10 mar. 2021.

Guia EduTec. [SÃO PAULO]: 2019. Disponível em: https://guiaedutec.com.br/. Acesso em: 10 mar. 2021.

CRESPO, Natália Deus de Oliveira; CRESPO, Larissa Codeço(org.) Ferramentas digitais para o Ensino: O Ensino Remoto Emergencial em Evidência / - 1. ed. - Recife: Even3 Publicações, 2020. 1 livro digital ; 85 p. : il. Disponível em:

https://publicacoes.even3.com.br/book/ferramentas-digitais-para-o-ensino--o-ensino-remotoem-evidencia-215565. Acesso em 20 maio 2021.

DIAS, Sara; MOREIRA, Jose Antônio; NUNES, Catarina S. Nunes. Escala de autoavaliação de competências digitais de professores: procedimentos de construção e validação. Belo Horizonte, v. 12, n. 2, p. 152-171, mai.-ago. 2019. Disponível em:

Saberes Pedagógicos, Criciúma, v. 5, n², maio/agosto 2021.- Curso de Pedagogia- UNESC 


\section{SABERES PEDAGÓGICOS}

Revista do Curso de Graduaçào de Pedagogia - Unesc

ISSN 2526.4559

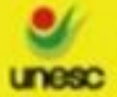

Oeles senentis

https://periodicos.ufmg.br/index.php/textolivre/article/view/16848/13609. Acesso em: 10 mar. 2021.

DIAS-TRINDADE, Sara; MOREIRA, Jose Antônio. Avaliação das competências e fluência digitais de professores no ensino público médio e fundamental em Portugal. Revista Diálogo Educacional, vol. 18, n. 58, p. 624-644, jul./set. 2018.

https://www.researchgate.net/publication/328007165_Avaliacao_das_competencias_e_fluenci a_digitais_de_professores_no_ensino_publico_medio_e_fundamental_em_Portugal. Acesso em: 10 mar. 2021.

FAIRCLOUGH, Norman. Discurso e mudança social. Brasília: Editora Universidade de Brasília, 2001.

GIL, Antonio Carlos. Como elaborar projetos de pesquisa. 4. ed. São Paulo: Atlas, 2007

FREIRE, Paulo. PEDAGOGIA DA AUTONOMIA: saberes necessários para a prática educativa. 6. ed. Rio de Janeiro: Paz e terra. 1997.

LAKATOS, Eva Maria; MARCONI, Marina de Andrade. Metodologia do trabalho científico. 9 ed. São Paulo: Atlas, 2010.

PUNHAGUI, Giovana Chimentão. Autoavaliação x autonotação: aproximações e afastamentos na formação de professores autorregulados. In: SEMINÁRIO DE PESQUISA EM EDUCAÇÃO DA REGIÃO SUL, 9., 2012, Caxias do Sul. Anais... Caxias do Sul, ANPED, 2012. Disponível em:

http://www.ucs.br/etc/conferencias/index.php/anpedsul/9anpedsul/paper/viewFile/1293/89 Acesso em: 25 jun. 2021.

SILVA, Andréa V. Mafra da. Tecnologias e Educação: o discurso da UNESCO. Educação (UFSM), [S.L.], v. 44, p. 65 1-17, 11 set. 2019. Universidade Federal de Santa Maria. http://dx.doi.org/10.5902/1984644437288.

SILVA, Ketia Kellen Araújo da; BEHAR, Patricia Alejandra. Competências digitais na educação: Uma discussão acerca do conceito. Educ. rev., Belo Horizonte, v. 35, e209940, 2019. Disponível em: https://www.scielo.br/scielo.php?script=sci_arttext\&pid=S010246982019000100419\&lng=pt\&nrm=iso. Acesso em: 11 mar. 2019.

UNESCO. Organização das Nações Unidas para a Educação, Ciência e Cultura. Padrões de competência em TIC para professores. UNESCO, 2009. Disponível em: https://goo.gl/6m4D87. Acesso em: 11 mar. 2019. 